P.S.-There is here a small geological class, the members of which take the "Geological Magazine," and read "The Silurian System." I have just re-perused (after a lapse of many years) the chapters on Drift at the close of Sir R. I. Murchison's celebrated work; and I cannot help thinking that the accurate descriptions and sound generalizations with which they abound, if re-published separately, would be of great service in moderating the zeal of modern subaërialists. I see Sir Roderick accounts for combes in the same way that I have lately been advocating in your pages. He says "These combes and valleys could have been modelled into their actual forms only by the action of a large body of water overspreading their entire area. . . . The nature of the excavation indicates also the action of water differently propelled at different times, perhaps by tidal currents, the directions of which were determined by local causes."-D.M.

\title{
THE ORIGIN OF BITUMEN,
}

\section{To the Editor of the Geological Magazing.}

SrR,-Y Your issue for March contains an article on "Petroleum and Oilfields," in which my views on the generation of bituminous substances are alluded to and controverted; at the same time a desire is expressed for further information respecting the occurrence of petroleum and bitumen in Trinidad.

If "E. C. H. D.," author of the article in question, had carefully considered the evidence adduced in the "Report on the Geology of Trinidad," he could scarcely have arrived at the conclusion that the direct production of bitumen from vegetable remains is doubtful, or the proofs of the production " defective," since this view is not proposed as a theory, but stated as an evident fact, beyond the range of discussion.

To detail, briefly as possible, the proofs on which this origin of bitumens is founded, viz.:- the existence over the bituminous districts of strata more or less charged with vegetable debris, with the woody matter in progress of conversion into bitumen, which conversion is induced entirely by internal chemical action, and independent of any extraneous influence, such as heat. This process is distinguished by the production of a dense, very black petroleum, which oozes out of the vegetable mass and only ceases to be formed on the complete change of the woody substance into bitumen; and is also accompanied by the formation of hydro-carbons. This oily fluid gradually solidifies (probably from the evaporation of a volatile solvent), leaving a black, very pure bitumen, locally known as "glance pitch." The residue of the wood is represented by a brownish black bitumen of impurer nature, in which all trace of vegetable structure has disappeared. The operation of this conversion is so intense, that hand specimens of the wood, when isolated from their earthy matrix and placed in a room, have continued to 
discharge the oily fluid for two months. ${ }^{2}$ The bitumen may be shown to have originated in these strata charged with vegetable remains, by the coast and ravine sections, where such strata are exposed containing wood in various stages of conversion; whilst intervening beds of sand or clay, in which no vegetable matter was ever contained, are entirely free from from all traces of bitumen, though equally adapted for fixing that substance, if it had been produced by distillation and risen from below.

It was not a part of the geological enquiry, respecting the bitumens of Trinidad, to investigate the chemical nature of this change of wood into the former; hence the term "special mineralization" was proposed as a record of the fact, and to distinguish this process from that which produces coal or lignite. It would seem to be due, however, to a reaction of the earthy matter of the containing stratum on the vegetable remains, since, where the latter predominate so as to form a pure mass of woody matter, lignite results ; beds of which also exist in the same districts, but are quite distinct from the bituminous strata, which only occur when a large amount of earth is associated with the woody substance. The forest swamp soils on the coast, in progress of formation at the present day, exhibit many analogies with the bituminous beds, viz., by containing up to 75 per cent. of vegetable débris, alternately overflowed by the sea and subjected at low tide to the influence of a powerful sun, an active chemical action, distinguished by the sensible production of sulphuretted hydrogen and other gases, is developed; and subsequent changes of level would reduce these swamp soils to precisely the same conditions as those presented by the bituminous strata.

We know that the mineralization of vegetable substances, whether tending to the production of coal and lignite, or bitumens, is accompanied by the production of gases and especially of hydro-carbons. Over the whole bituminous area in Trinidad and Venezuela, wherever the liquid petroleums are issuing from the surface, they are accompanied with an emission of gas more or less inflammable, and frequently associated with water and mud. It is evident that the pressure of the gases generated in the production of the bitumens, is the active agent in the delivery of the oil and water which arrive at the surface perfectly cool. These oils and pitchy substances rapidly lose their volatile solvent principles and consolidate; where exposed to the solar action a further evaporation takes place and a hard brownish black bitumen remains, possessing a considerable proportion of earthy impurity. Wherever the surface is favourable for the accumulation of the pitchy discharges, the bitumens, still plastic, flow together from various centres of emission and coalesce into a more or less extensive aggregation of the substance. The "Pitch Lake" of Trinidad is merely an instance of this coalescence on a larger scale than usual.

Many specimens of vegetables, undergoing this species of mineralization, were subjected to the late Mr. Stermann Crüger, Colonial

- Numerous specimens illustrating the change of wood into bitumen were deposited in the Museums of Jeroneport, and Port of Spain, Trinidad. 
Botanist for the Island of Trinidad, and a most skilful observer in vegetable physiology, who, though originally opposed to the view of the direct conversion of wood into bitumen, was obliged to yield to the evidence of his own researches, as detailed in his descriptions of the fossil plants collected during the survey, ${ }^{1}$ viz. "In nearly all these specimens, or at least where there is a strong probability of their representing wood in actual state of transformation into asphaltum, an evident parallelism exists with lignite." . . . . . "As the chemical process, which transforms wood into asphaltum, must be very similar to that which changes it to lignite or coal, we conclude, not too rashly, I think, in considering them to be in a transitory state."

This view of the production of bitumen was never pretended to be new, since Bischof showed, twenty years ago, that bituminous substances are the result of direct conversion from wood and vegetable remains, and adduced the chemical formula involved in the process ; ${ }^{2}$ but it was proved that the bitumens, so widely distributed in Trinidad, and the adjacent part of South America, are positively due to this cause, which operates under normal conditions of temperature and climate; not, perhaps, to be observed in a northern country with an average temperature of $50^{\circ}$, but fully developed in tropical latitudes with constant temperatures of $80^{\circ}$ and upwards. Such being the case, and every phenomenon relating to the bitumens in these countries being easily explained according to this view, and admitting of explanation according to no other view, why hesitate to extend this origin of bitumens to other regions and other conditions, where the mode of production of the oil, petroleum, or pitch, may not be so susceptible of investigation or satisfactory solution?

With respect to distillation-in what instance can it be shown that the bituminous matter of a carbonaceous stratum has been volatilized by the proximity of heat and condensed at a certain distance in other strata? Experience rather teaches us that it would be entirely dissipated or retained in the pores of the parent stratum in the state of gas. The more or less bituminous nature of a coal seam does not depend on its being in the latter case deeper seated, and nearer the influence of heat; since, as an instance in this district (South Yorkshire), the most highly bituminous coal - the "Silkstone"-is situated near the base of the series and 300 yards below the "Barnsley," or "hard coal," distinguished by a very slight bituminous content; showing that the dry nature of a coal does not depend on the separation of its bitumen by heat, but is due to the original nature of the component vegetables, or to the nature of the mineralization experienced. Again, these natural bitumens, viz., pitch and petroleum, do not correspond with the results of distillation, but are precisely the products that would arise in the direct conversion contended for.

The production of bitumen from animal remains is not a part of the question, which it is necessary to illustrate in this communi-

1 Rep. Geol. Trinidad, Appendix $\mathrm{K}$.

2 Chem. and Phys. Greol. Carendish Soc. Trans. vol. i. pp. 288-291. 
cation; but since "E. C. H. D." hazards the observation that "bitumen or petroleum having in some instances arisen from a "special mineralization' of animal remains, is a doctrine by no means generally accepted;" to adduce only one of many well known instances tending to confirm the truth of this view, also, viz., that of the mountain limestone of the adjacent district (Derbyshire), which almost wherever highly fossiliferous contains bitumen in cracks and joints of the rock, evidently derived from the animal substance of the fossil remains, and not due to the influence of heat.

In conclusion it only remains to ask, what necessity for the mystery and difficulty with which the subject is involved in "E. C.H.D.'s" estimation? To our mind the generation of bitumens is easily and simply explained by the operation, at the prdinary terrestrial temperatures, of chemical laws of which we have cognizance, and the phenomena attending the emission of the oils and associated gases, are equally explicable by known physical laws. The facts and circumstances connected with the occurrence of petroleum and bitumen, which induce "E. C. H. D." to accept a " distillation theory," have a directly contrary influence on us, and convince us that these substances are the result of a law of mineralization operating as regularly, and almost as extensively, as that which produces coal and lignite.

SheFField, March 26, 1866.

Yours respectfully, Gro. P. WaLL.

\section{To the Editor of the Geocogican Magazink.}

Dear SIr,- Since I sent you the last communication on the junction of the Chalk and Thanet Sands, ${ }^{1}$ Mr. T. McKenny Hughes has read a paper before the Geological Society on the same subject. ${ }^{2}$ His theory of the formation of the green-coated flints is that, they are the result of the solution of the chalk by carbonated water after the deposition of the Thanet Sands; the objection to this appears to me, that by such means we should not have that remarkably even surface presented by the Chalk at its junction with the Thanet Sand, nor that marked peculiarity of the green-coated flint, resting on other flints not presenting this peculiarity, moreover where the chalk is worn by the action of carbonated water as in the pipes and furrows of the chalk, we find a most uneven surface presenting no appearance like that of the junction of Chalk with the Thanet Sands. The tabular flint, immediately below the green-coated flints, is by no means so continuous as to present an obstacle to the passage of water, sufficient to account for the even undissolved chalk, and wherever pipes do occur beneath the Thanet Sands (which, as far as I can ascertain, is only the case where the latter is near the surface), the green-coated flints sink down into the pipe with the tabular uncoated flint, which is always to be distinguished from the former.

I believe the tabular flint has been formed subsequently to the Thanet Sands, and the green-coated flint resting upon it.

Stourmouth, April 18th, 1866.

$$
\text { Yours, etc., GroRge Dowken. }
$$

1 See ante, p. 210. 